\title{
Research Paper: Assessment and Analysis of Rural Women's Indigenous Ecological Knowledge and its Use in Sustaining Natural resources: A Case Study of Villages in the Counties of Nishapur and Firuzeh
}

\author{
khadijeh Bouzarjomehri ${ }^{*}$
}

1. Associate Professor, Department of Geography, Faculty of literature and humanities, Ferdowsi University of Mashhad, Mashhad, Iran.

\begin{tabular}{|c|c|}
\hline $\begin{array}{l}\text { Use your device to scan } \\
\text { and read the article online }\end{array}$ & Citation: Bouzarjomehri, Kh. (2018). Assessment and Analysis of Rural Women's Indigenous Ecological Knowledge and its \\
\hline 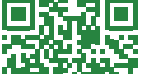 & $\begin{array}{l}\text { Use in Sustaining Natural resources: A Case Study of Villages in the Counties of Nishapur and Firuzeh. Journal of Sustainable } \\
\text { Rural Development, 2(1-2), 17-28. https://doi.org/10.32598/jsrd.01.03.270 }\end{array}$ \\
\hline arifis & dol: $:$ https://doi.org/10.32598/jsrd.01.03.270 \\
\hline
\end{tabular}

Article info:

Received: 08 Jan. 2018

Accepted: 08 July 2018

Keywords:

Rural women's indigenous knowledge, Indigenous ecological knowledge, Indigenous pedological knowledge, Nishapur and Firuzeh counties

\begin{abstract}
A B STRACT
Purpose: This study has been conducted with the overall objective of identifying the ecological knowledge of rural women, specifically their knowledge of local pedology, through a gender analysis approach.

Methods: The study adopts an exploratory, descriptive-analytical method, using both quantitative and qualitative methodologies. The population of the study includes female-headed households in villages with a population of more than 30 families in Nishapur and Firuzeh where women are familiar with farming activities and have actively participated in the agricultural production. To determine the sample size, first, through Cochran's sample size formula, 22 villages were selected out of 357 villages in the population. Then, of the total number of 8810 women in the sample villages, 150 were selected through simple random sampling for questioning and semi-structured interviews.
\end{abstract}

Results: The findings revealed that the level of rural women's awareness of their ecological environment is relatively high, which is due to living experience in rural areas for centuries. This experience has been orally transmitted from one generation to another.

Conclusion: Their knowledge of local pedology is also high, nearly conforming to the scientific classifications of soil. If combined with the official knowledge, it can be used to complement the data in local studies and in the sustaining of natural resources.

\section{Introduction}

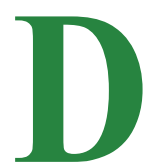

uring the past half-century, application of modern knowledge and technology has led to major changes in services and production processes in villagers' lives. At the same time, use of some modern technologies has created certain social, economic and environmental problems which have become concerns for thinkers and theoreticians. One of the available options for addressing

* Corresponding Author:

khadijeh Bouzarjomehri, PhD

Address: Department of geography, faculty of literature and humanities, Ferdowsi University of Mashhad

Tel: +98 (51) 38830910

E-mail:azar1334@gmail.com 
these concerns is to refer to the empirical knowledge of ancestors or the indigenous knowledge (Ahmadrash \& Daneshmehr, 2015). Villagers' knowledge plays a major role in the protection of biodiversity and the sustainable management of natural resources and is a valuable input in planning and decision making for rural development. Studies have shown that, in most cases, many things can be learned from villagers as they have vast knowledge in various fields such as ecology, botany, various plant diseases, pedology, climatology, etc. This can be attributed to years and centuries of experience. Besides the indigenous knowledge, there is an official knowledge which is the result of scientific activities in universities and research centers and follows certain principles pertaining to scientific methodology. Official knowledge is hardly influenced by values and beliefs and is created in research centers with the aim of expanding human knowledge. Its experimental aspect is very strong since it is based on the philosophy that only concrete and tangible facts are acceptable. Regardless of such differences between indigenous and official types of knowledge, these two are not in contrast but are considered complimentary (Papzan et al., 2003).

Experts have provided various definitions for indigenous knowledge, each considering it from a specific point of view. Most such definitions make use of terms such as systems of indigenous knowledge, indigenous technical knowledge, ethnic science, indigenous ecology, indigenous traditional science, people's science, and rural science, among which systems of indigenous knowledge (IK) has been used the most (Emadi \& Abbasi, 2004; Bouzarjomehri, 2003). Generally, indigenous knowledge is considered as a part of the unique culture of an ecosystem or region, acquired through experience, with the purpose of adapting to the specific environmental conditions of ecosystems. It gradually becomes a part of the society's productive and social culture; it is suggestive of the adaptation to the environment and the creation of a rational relationship between humans and their habitat (Jomehpour, 2005). Some even consider indigenous knowledge as a key element of wealth and the main social capital with which to gain control over life (Gorjestani, 2000). However, indigenous knowledge is generally a small set of methods created and developed over time by the people of a specific society through experience with the surrounding environmental phenomena; as the environmental conditions change, indigenous knowledge also varies and becomes dynamic, thus providing stability for the society and the environment (Warren, 1996). Similarly, the international community has recognized the role of indigenous people in environmental and natural resources, such that the international union for "conservation of nature" which was established in the 1980s. It is stated that, most often, traditional societies have a deep knowledge of the ecosystems with which they are interacting and practice effective methods to sustain the resources (Azkia \& Imani, 2008). Moreover, the report of World Commission on Environment and Development in 1987 emphasized the critical role of indigenous people in sustainable development (McGregor, 2004). The United Nations' conference on environment and development and the UN convention on biological diversity have also emphasized the role of indigenous people and their knowledge in the sustainable management of the environment and natural resources.

Environmental and socio-economic problems, caused by the application of ill-advised technologies and the biased utilization of western culture in developing countries, have been the reason for the recent attention to indigenous knowledge. This has gradually led to the emergence of endogenous approaches and theories of sustainable rural development. Influenced by these new approaches, local potentials, rural men and women, and their knowledge and skills have come to the attention of experts of development and sustainable environment. As mentioned before, although some differences exist between indigenous knowledge and formal knowledge, these two should not be considered opposite; rather, they complement each other, and combining them can yield results that are not possible using each one in isolation. Moreover, according to "gender analysis", differences exist among men and women in terms of knowledge and capacities. These differences, which are due to the different roles and activities of those people, should be identified and utilized in development plans (Grenier 1998). To this end, drawing on the framework of gender analysis, the present study seeks to assess and analyze the ecological knowledge of rural women in Nishapur and Firuzeh counties in Khorasan Razavi province, Iran. The study specifically aims to identity their awareness in terms of indigenous penology and to pinpoint the role of this knowledge in the management of natural resources and sustainable development.

\section{Literature Review}

Indigenous knowledge means traditional and local knowledge, and this is what differentiates this type of knowledge from other types of knowledge provided by official research centers (DeAngelis, 2013) This knowledge is a part of the national wealth of a region and includes values, methods and scientific tools. It is the result of centuries of trial and error in natural, social and 
socio-cultural environments and is mostly transmitted orally from one generation to the next (Kalanda-Joshua et al., 2011). It is simple, scientific, graspable, local, and comprehensive (Nkomwa et al., 2014) and specific to a particular geographical region to provides a basis for decision making in the development process (Tirivarombo \& Hughes, 2011).

The term ecology is derived from the Greek word "Oikos" meaning house, habitation, dwelling place and "Logos" meaning study. Therefore, in terms of its etymology and literal meaning, it is the study of the habitat of living things, but it is used to refer to "the influence of the environment on living things, the influence of living things on the environment, and the mutual interactions among living things".

The term ecology was first introduced by the German biologist Ernst Haeckel in 1869 (Amiri Ardakani, 2009). Indigenous knowledge and ecological knowledge are interrelated. This is because our ancestors and forefathers tried to survive and satisfy their needs by studying their environment and gaining experiences, which has come to be known as indigenous ecological knowledge or native ecology. However, there is a difference between men and women in terms of this knowledge due to their different roles and activities in various societies. In other words, the knowledge is somehow gender-related. Though possessed by all the members of a society, i.e. from children to the elderly and from men to women, ecological endogenous knowledge varies in terms of quality and quantity and depends on a myriad of factors such as age, level of education, gender, social and economic situation, daily experiences, different roles and responsibilities in family and society, levels of potential, competence and acquired skills, level of independence, and the degree of control on natural resources (Grenire.1998). Experience shows that there are relationships among sustainable development, protection of natural resources, biodiversity, systems of indigenous knowledge, cultural and gender diversity, and intellectual property rights (Quiroz, 1994). It has also become clear that gender is a cultural construct, affecting the behavior of men and women in the society, the type of work they do, and the way it is done. Gender differences are caused by production responsibilities and duties and lead to the creation of specific experiences, knowledge and skills (Housinga Noroum et al., as cited in Feldstein and Poats, 1988). As certain tasks are considered to be the usual responsibility of women, some types of knowledge is within their specific realm. Indeed, all types of knowledge can be differentiated by gender because knowledge is a part of the social content and gender is a major aspect of this content (Warren, 1988, as cited in Emadi and Abbasi, 1999). They develop their skills over time and gain some expertise based on gender, which definitely affects the level of accessibility to, application of, control over and various insights regarding innovation and application of various new techniques and skills (Appleton, 1993). Therefore, ignoring this specific type of knowledge can push development plans to failure and pose major challenges to sustainable development (Fernandez, 1994). Awareness of the needs and indigenous knowledge specific to women will not only make development plans more effective but also predisposes appropriate methods to rectify socio-economic inequalities embedded in development policies, plans and programs (Housinga Noroum et al., 1999). Taking a gender analysis approach, studies indicate that women, compared to men, are more inclined toward nature and protecting the environment (Mcstay \& Riley, 1983). Some studies regarding indigenous knowledge are indicative of the valuable ecological knowledge of rural women; In his study on the management of water resources in Sri Lanka, Wishewa (1993) showed that women play a major role in ecological sustainability and possess considerable indigenous knowledge and a series of traditional water supply strategies, including provision, refining and storing. Similarly, In a study entitled "Indigenous knowledge in seasonal rainfall prediction in Tanzania", Chang'a (2010) showed that women possess high levels of ecological knowledge in this regard. Golzari and Mirdamadi (2010), in an article entitled "Indigenous knowledge, an applied approach in sustainable development", emphasized that the active participation of rural men and women in the sustainable development of villages is possible unless there is a belief in their indigenous knowledge, insights and skills. Vazin and Roknoldin Eftekhari (2012), in an article entitled "The role of indigenous knowledge in water and soil resources preservation from the perspective of villagers: A case study of Khvoresh Rostam district, Khalkhal", concluded that indigenous knowledge is aligned and compatible with sustainable development approaches. Similarly, in their article entitled "Identify in indigenous knowledge and its application in rural crisis management by emphasizing drought, flood and earthquake: A case study of Zuzan in Khaf county", Bouzarjomehri and Javanshiri (2015) concluded that, with years of experience and a thorough understanding of atmospheric precipitation and its time of occurrence, men and women in the region have long created local structures that are effective in reducing the risk of floods and reinforcing underground water reservoirs. Amiri Ardakani (2016), in his book Indigenous knowledge in pedology, emphasizes that acquiring a thorough understating of soil and 
protecting it is an inevitable necessity. This is because soil is the foundation of all agricultural activities and the survival of humans, animals and plants is not possible without it. According to the author, to protect soil, both indigenous and formal types of knowledge should be used concurrently.

In spite of such studies, villagers' skills and indigenous knowledge, specifically in management and exploitation of natural resources, are not fully recognized and still remain neglected; few studies have ever adopted a gender approach. This is because, until the 1980s, due to the dominance of modernization in developing countries, including Iran, indigenous knowledge was rejected by policy makers and planners. Also, those with this kind of knowledge, i.e. farmers in local communities, were considered uneducated and retrogressive. However, recent studies have revealed that indigenous knowledge and methods are beneficial to the protection of the environment and sustainable livelihood, and, before their demise, they should be discovered, extracted and wisely protected and improved. The purpose of the present study is, thus, to extract, record, and document the indigenous ecological knowledge of rural women to protect and enhance the extant database and utilize it for environment conservation. This is to be always borne in mind that this type of knowledge has been tested throughout centuries, has no environmental ramifications, and can be utilized in combination with official knowledge to sustain natural resources.

To comprehend the ecological knowledge of rural women in the county of Nishapur, which has a long history of residence, seven factors were taken into consideration in this study. The data on three of those factors, namely indigenous pedological knowledge, various atmospheric precipitation and local winds, were collected qualitatively as specified in the conceptual framework of the study (Figure 1).

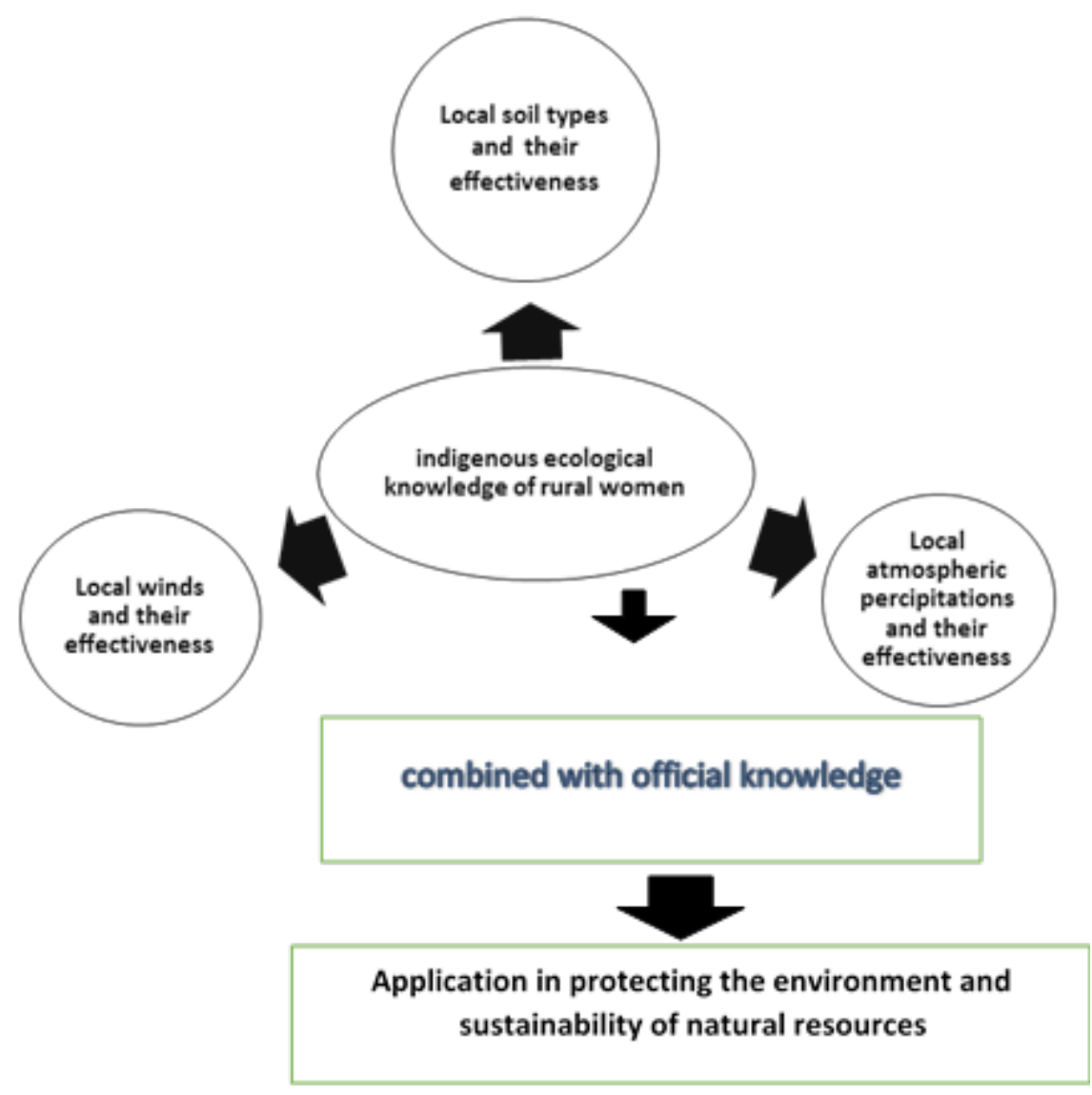

Figure 1. Conceptual framework of the study 


\section{Methodology}

This study is an exploratory, descriptive and analytical one based on the data gathered through quantitative and qualitative methods. Using structured and semistructured questionnaires along with individual and group interviews, the ecological and local pedological knowledge of rural women was discovered, described and analyzed. The population of the study included the rural women older than 25 who resided in villages with a population of more than 30 families in Nishapur and Firuzeh counties and participated in agricultural activities. According to the statistics of the year 2011, in the 357 villages of these two counties, agricultural activities are dominant. Using Cochran's sample-size formula, 22 villages were chosen as a sample. Moreover, to consider the population factor in accordance with Probability Proportionate to Size (PPS), sampling was done in accordance with the population of each village. Since rural women active in the agriculture sector were considered as the unit of analysis in the study, in the second stage, of the total 8810 families, 150 were selected through Cochran's sample size formula. To this end, first, through group interviews and snowball sampling, the indigenous ecological knowledge of different villages was obtained.
To assess the knowledge of the women in the sample, they were questioned, and their responses were evaluated quantitatively. For instance, regarding the factor "familiarity with regional medicinal plants", the knowledge of those who named fewer than five plants was evaluated as low, those naming five to 10 plants were considered average, and the knowledge of those who named more than 10 plants was evaluated as high.

The area under study included the two counties of Nishapur and Firuzeh, located in Khorasan Razavi province. The county of Nishapur has four districts, and the county of Firuzeh, formerly known as Takhtjolge and a district of Nishapur county until 2007, has the two districts of Taqankuh and Markazi. Eighteen of 22 villages in the sample belonged to Nishapur, and four belonged to Firuzeh. The corresponding locations are depicted on Figure 2. Overall, the majority of the county's villages and the sample villages are located on the alluvial plains of Nishapur, which has a deep type of soil with a heavy texture. Moving along the mountainous regions of the northwest and the south, one can see the shrinkage of deep, fertile soil.

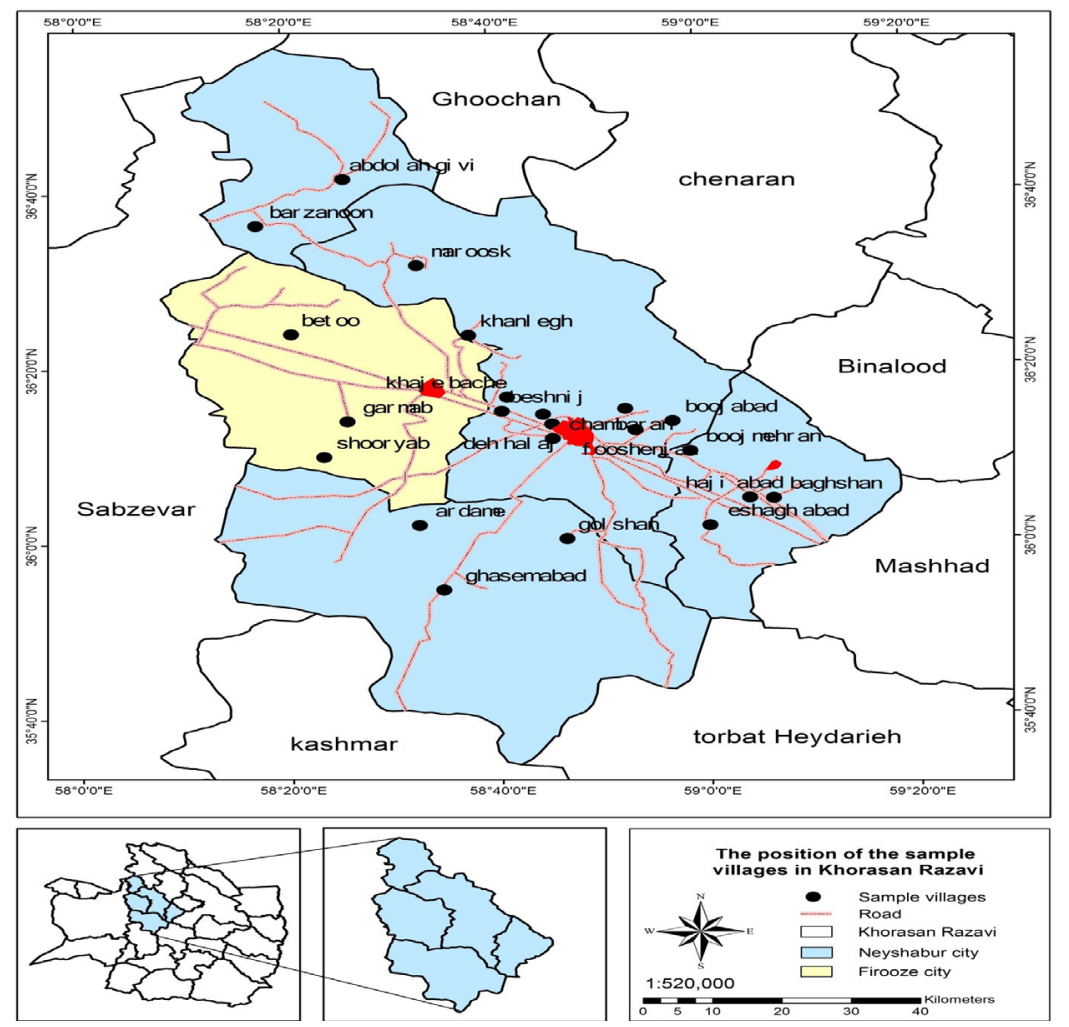

Figure 2. Location of the sample villages 


\section{Reliability and validity of the study}

In this study, various methods and techniques were used to increase the reliability and validity of the research. For instance, although the study was mainly done using qualitative methods, statistical methods were also used to increase its validity. To this end, the qualitative factors were first quantified and then, using statistical packages, the findings were presented quantitatively too. The data were gathered through collaborative evaluation, individual structured and semi-structured interviews according to snowball sampling and interviews with the rural women in the sample. To establish the reliability and validity of the data, efforts were made through the researchers' long stay in the region, group interviews with local experts and consultation with external specialists.

\section{Findings}

\subsection{Individual characteristics of the sample}

The sample included rural women older than 25 who lived in 22 sample villages in Nishapur and Firuzeh counties. They helped their spouses in agricultural activities where the main job of the head of the household was also agriculture. The selection of this age group was based on the fact that older women generally possess higher levels of indigenous and ecological knowledge. Of the 150 rural women in the sample, 94 percent were married and 6 percent were widows serving as the heads of their families. The women in the age group of 35 to 45 accounted for 30 percent and those older than 65 comprised 4 percent of the sample. They had the highest and the lowest distribution respectively.

\subsection{Environmental knowledge of rural women}

In this study, environmental knowledge refers to the general knowledge of the sample women regarding the physical environment of the village. According to the field findings, as presented in Table 1, 58 percent of them knew the name of their district, 43 percent knew the distance of the village to the main road, and 47.6 percent knew the distance between their village and the city of Nishapur. Instead of kilometers, women usually used time distances. Some of them also used Farsang (equal to six kilometers) to express the distance. The point about which they had the lowest knowledge was the number of families inhabiting the village and the village population. In this case, only 34 percent of the women could mention relatively correct numbers.

\subsection{Ecological knowledge of the rural women}

To assess the ecological knowledge of the women, seven factors were taken into account, including "number of the water sources in the village", "local atmospheric precipitation", "various soil types in the village", "names of self-growing plants", "names of local winds", "names of surrounding mountains and hills", and "names of surrounding forests and grasslands". As reported in Table 2 , in most of these factors, the women possessed high levels of knowledge, with the highest being related to various atmospheric precipitation, self-growing plants, and the number of the water sources in the village. The lowest level of knowledge was about the surrounding forests and grasslands and the areas farther away from the village. This can be attributed to the long distance between these places and their place of residence together with gender-based types of labor. Indeed, such women do not have much to do in these areas; hence, they have lower levels of knowledge than men.

Among the studied ecological factors presented in $\mathrm{Ta}-$ ble 2, the data on the women's indigenous knowledge regarding different types of wind, atmospheric precipitation and types of local soil and their use were gathered qualitatively, as summarized in the next section.

Table 1. Level of the environmental knowledge of the sample rural women

\begin{tabular}{ccccccc}
\hline $\begin{array}{c}\text { Number of } \\
\text { families }\end{array}$ & $\begin{array}{c}\text { Distance from } \\
\text { Nishapur }\end{array}$ & $\begin{array}{c}\text { Distance to the } \\
\text { main road }\end{array}$ & $\begin{array}{c}\text { Name of } \\
\text { the district }\end{array}$ & $\begin{array}{c}\text { Village's distinctive } \\
\text { point }\end{array}$ & Adjacent villages & $\begin{array}{c}\text { Level of } \\
\text { awareness }\end{array}$ \\
\hline 28.8 & 36.6 & 43.0 & 38.5 & 21.8 & 1.3 & low \\
37 & 15.9 & 14 & 3.4 & 27.2 & 8.7 & average \\
34.2 & 47.6 & 43 & 58.1 & 50 & 89.9 & high \\
\hline
\end{tabular}


Table 2. Percentages of the sample women's ecological awareness of their village and the surrounding areas

\begin{tabular}{|c|c|c|c|c|c|c|c|}
\hline $\begin{array}{l}\text { Names of the } \\
\text { surrounding } \\
\text { forests and } \\
\text { grasslands }\end{array}$ & $\begin{array}{l}\text { Names of the } \\
\text { surrounding } \\
\text { mountains }\end{array}$ & $\begin{array}{l}\text { Names of lo- } \\
\text { cal winds }\end{array}$ & $\begin{array}{c}\text { Names of } \\
\text { self-growing } \\
\text { plant } \\
\text { And their use }\end{array}$ & $\begin{array}{l}\text { Name of } \\
\text { soil type } \\
\text { and its } \\
\text { use }\end{array}$ & $\begin{array}{l}\text { Local } \\
\text { atmo- } \\
\text { spheric } \\
\text { precipi- } \\
\text { tation }\end{array}$ & $\begin{array}{c}\text { Number of } \\
\text { water sources } \\
\text { of the village }\end{array}$ & \\
\hline 43.3 & 17.1 & 6.5 & 7.4 & 5.4 & 0 & 4 & low \\
\hline 24.4 & 36 & 43.5 & 29.5 & 38.3 & 27.2 & 37.7 & average \\
\hline 32.2 & 46.8 & 50 & 63.1 & 56.4 & 72.8 & 59.3 & high \\
\hline
\end{tabular}

\subsubsection{Variety of local atmospheric precipitation}

Rural women in the sample were familiar with the atmospheric precipitation of their region although they did not know about its wherefores and its levels in millimeters. However, they knew the local names of different types of precipitation as well as their time, intensity and effectiveness. Overall, four types of rain are well-known in the region:

1. Spring deluge, which is known as "Jeleh" but has various names such as "Gel kub", "Jeleh kub", "Khargaz baran", "Tule" and "Ish". These are mostly Turkish names. The rain usually falls up to 60 days after the Persian New year's Day and, in most cases, damages agricultural products.

2. Mild rains which fall from the end of March up to the middle of spring and are very suitable for agriculture. They have various names such as "Narm baran", "Nazm”, “Alaf kesh", "Sefid Baran", "Pish nam', and "Narmeh baran".

3. "Shishe" rains are those falling every 10 days following Norouz (i.e. Persian New Year) and well-known all over Khorasan province.

4. Autumnal rains which are known as "Mizan" or "Ghous" are very useful for dry farming in autumn.

\subsubsection{Variety of local winds}

Rural women in the sample were familiar with various types of local winds, their directions and effectiveness, as summarized in Table 3.

Considering the information in Table 3 and the comparisons with the official data, certain results are elicited below.
Although rural women in the sample were not familiar with the air masses, regional winds and their causative factors, they were familiar with the names of local winds, their directions, intensity, characteristics, and effectiveness.

Although the source and direction of major local winds are similar, in various regions, they assume different names; for instance, the eastern wind "Dizbad" is used in both Zebarkhan and Markazi districts, but, in eastern parts of the county, it is known as "Nishapur wind" and, in desert regions of Nishapur, it is called "Tamouzi wind" or "Tefbad". Using such local information can help enrich the knowledge about the region.

\subsubsection{Pedology and its uses}

Since the majority of rural women in this region actively participate in agricultural activities, they are familiar with the characteristics of soil types in their villages. As shown in Table 2, overall, 94.7 percent of the women in the sample had average and above-average knowledge of different soil types in the village. They were aware of the effects of soil type on farming production yield and seemed to be experimentally familiar with various usages, capabilities, problems and methods related to improving the soil in their villages. Qualitative interviews revealed that they were familiar with various types of soil in their villages and knew their local names, physical characteristics such as color, texture, need for water as well as limitations and usages. These data are presented in Table 4 for each sample village.

Comparing the official pedological information of the region presented in Table 5 and the women's pedological knowledge, one comes to the following two findings: 
Table 3. Local winds in the study area according to the women's indigenous knowledge

\begin{tabular}{|c|c|c|}
\hline Effectiveness & Features & Names of local winds \\
\hline $\begin{array}{l}\text { In the past, it was used for cleaning the } \\
\text { harvest and ripening of the product. It } \\
\text { damages if severe. }\end{array}$ & $\begin{array}{c}\text { Eastern wind that blows in summer and in the afternoons, at } \\
\text { times stiffly, and destroys the products; in eastern villages it is } \\
\text { known as Dizbad and in western villages as Nishapur or Bluk } \\
\text { wind. }\end{array}$ & $\begin{array}{l}\text { Dizbad (aka Siahbad } \\
\text { Tamouzi, Tefbad, Doz- } \\
\text { dbad, Bad-e-bluk and } \\
\text { Nishapur) }\end{array}$ \\
\hline $\begin{array}{l}\text { This type of wind is light and moist, } \\
\text { without any damage. }\end{array}$ & $\begin{array}{l}\text { A moist wind that blows from the west and has a specific } \\
\text { name in each region. }\end{array}$ & $\begin{array}{l}\text { Nishapur wind (aka city } \\
\text { wind, Gorgan wind) }\end{array}$ \\
\hline $\begin{array}{l}\text { In the past, in eastern parts of the coun- } \\
\text { ty, it was used for cleaning the harvest. }\end{array}$ & $\begin{array}{l}\text { Light and moist, blows from north, causes the temperature to } \\
\text { fall in winter }\end{array}$ & $\begin{array}{l}\text { Quchan wind (aka North } \\
\text { wind, Nazmbad) }\end{array}$ \\
\hline $\begin{array}{l}\text { Sometimes leads to tornadoes and } \\
\text { destruction }\end{array}$ & $\begin{array}{c}\text { A rather light wind which blows from north in summers, } \\
\text { continuation of the } 120 \text {-day wind, at times is accompanied by } \\
\text { dust and black wind. }\end{array}$ & $\begin{array}{l}\text { Qebleh wind (i.e. south } \\
\text { wind) }\end{array}$ \\
\hline $\begin{array}{l}\text { Cools the air and causes destruction if } \\
\text { strong }\end{array}$ & $\begin{array}{l}\text { Villages located at the foot of the mountains are exposed to } \\
\text { this type of wind which blows toward the villages during the } \\
\text { day. }\end{array}$ & Mountain wind \\
\hline $\begin{array}{l}\text { Or Derakharooskon wind which fertilizes } \\
\text { trees }\end{array}$ & $\begin{array}{l}\text { Light summer breeze which, in Bouzhmehran and Bouzhabad, } \\
\text { is called with this name. }\end{array}$ & $\begin{array}{l}\text { Derakht arooskon wind } \\
\text { (Zolal wind) }\end{array}$ \\
\hline Creates dust & Wandering winds & Daleh wind \\
\hline Severe tornadoes & When Dizbadn and Quchan winds blow simultaneously & Dolakh wind \\
\hline
\end{tabular}

Table 4. Indigenous pedological knowledge of the rural women in the studied sample

\section{Applications}

\section{Characteristics of soil types in the sample villages}

Black and at times dark yellow; due to its combination of rocky and sandy soils, known and "domouyeh"; has a medium texture, good quality and fertility; needs low water

Suitable for all types of farming specifically wheat, barley and dryland watermelon production

Suitable for planting wheat, barley, beetroot, cotton, watermelon, dry land almond production; due to its adhesiveness, used for thatch in construction of houses, bricks, and furnaces; used in refining grape juice

With soil improvement, it is suitable for growing watermelon, cotton, onion, tomato, potato and all types of irrigated farming, even wheat, barley and dry land watermelon production.

With soil improvement in some villages, suitable for wheat, barley, cotton farming along with watermelon and almond dry land farming

Arid and without any use Has to be revived for farming
It is fine-grained, heavy-texture clay, reddish and sometimes yellowish to white.

Due to its fine texture and rigidity, it has low water retention capacity and is impervious.

In case of improvement with sand, grit or animal manure, it can be suitable for irrigated agriculture.

It is black and at times reddish with soft alluvial sediments and contains river and stream mud.

It has a medium texture, low water retention capacity, and high need for water.

It is mostly used for reducing the weight of clay and Shakhi soils. If combined with animal manure, it is suitable for farming.

It contains gravels or rubbles and has yellow, black, and dark red colors.

It is created at the banks of canals and feet of mountains around villages by erosion.

Due to its heavy texture and rapid passage of water, it needs more irrigation and has a very low agricultural yield.

A type of soil, usually white, arid and with salt flats of different names

The soil of ruined houses is called Khakshoureh or "Bekr". For the revival of farms, the earthen walls of ruined houses are demolished, and the soil is transported to the farm.
Local names of soil types

Natural soil, Domoubeh, Choqoki (sparrow)

Shakh or addagh Tarousak and Tlous

Sand or Nahli, Ghami, Shazdeelmi

Chali or Kamreh

Olangi, Tanbaltosghol, Oladagh

Khakshoureh 
Firstly, comparing the pedological map of the region and its guideline table (Aram Afaghi, Manouchehr Jalilian, Iran Geography Company) where textures, physical features, limitations and usages of soils are shown with the indigenous pedological knowledge of the studied women, one can see that the two are very consistent and, at times, the women's' knowledge is more detailed and local; therefore, it can be used to complement the official ecological information.

Secondly, from the villagers' point of view, the most important soil characteristics are softness, suitable texture, water retention ability and high product yield. In terms of mechanical-physical properties, soil porousness, and the capacity of available water, the pedological classification made by indigenous women conforms to the scientific classification offered in Table 5 (Rattan, 1999). In this scientific classification, types of soil suitable for agriculture start with sandy lime which is very soft and less than 10 percent of that is coarsely grained. It is highly suitable for agriculture and has a water retention ability of $30 \%$. This is generally known in the region as "Domouye", a normal fertile soil or combined soil. It can be mixed with gravel soil with a light texture of which 60 percent is coarsely grained. Possessing high water penetrability and severe limitations, this soil is locally known as "Chali" or "Kamare and mainly found at the foot of mountains. Therefore, women's knowledge of the physical properties of soil is nearly compatible with the official classification, with the sole difference that women have no knowledge of the proportion figures, percentages and numbers.

\section{Conclusion}

It was found that the rural women in the studied region have average and above-average awareness of their physical environment, but their qualitative information is more than their quantitative and statistical knowledge. Their lowest level of knowledge pertains to the exact number of families in the village and its population. Concerning the ecological information, they have the highest level of knowledge about self-growing plants and various soil types in the village, but their lowest level of information pertains to the names and features of the forests, grasslands, and mountains surrounding the village. This can be attributed to the long distance between these places and their place of residence. To sustain their families, the rural women in the region grow agricultural products, through which they have become familiar with the ecological features of their environment over centuries. Their very knowledge of the environment and its potentials has been effective in sustaining the environment and natural resources. Using their familiarity with the environment and its ecological potentials, they grow farming crops without exerting much pressure on nature. They know how to treat their environment so that it can be exploited in the long run. The findings of the study are in line with the findings of Wisheva (1993), Chang'a (2010), Golzari and Mirdamadi (2010), and Vazin and Roknoldin Eftekhari (2012) all of which have emphasized that ecological types of knowledge are aligned with sustainable development. Another finding was that the ecological knowledge of the rural women in the region contains precise local information which can be used as a complement to official statistics. in case the experience of local people is neglected, development planners will be deprived of part of valuable insightful sources which are readily available. Therefore, the following suggestions seem to be in order:

Table 5. Comparison of indigenous soil classification with the scientific classification

\begin{tabular}{ccccccc}
\hline Limitation & $\begin{array}{c}\text { Water retention } \\
\text { capacity }\end{array}$ & $\begin{array}{c}\text { Water pen- } \\
\text { etrability }\end{array}$ & $\begin{array}{c}\text { Percentage of } \\
\text { coarse grians }\end{array}$ & Rigidity & Soil texture & $\begin{array}{c}\text { Indigenous soil } \\
\text { name }\end{array}$ \\
\hline none & $>30$ & severe & $<10$ & very soft & lime sand & Domouye \\
low & $20-30$ & almost sever & $10-20$ & soft & alluvial sand & Nahli or Nahri \\
average & $8-20$ & slow & $20-40$ & A little rigid & lime clay & Shakhi or Zad \\
very severe & $2-8$ & rather slow & $40-60$ & very rigid & slit clay & Tlous \\
severe & $<2$ & very severe & $>60$ & light texture & gravel soil & Chali \\
\hline Rattan, L. (1999). Permanent use of water and soil resources & & & & C JSRD
\end{tabular}


a). Exploration, extraction, and documentation of indigenous ecological knowledge of different villagers is to be done on a gender basis. This is because, over the centuries, owing to the separation of gender roles, men and women have gained rather different experiences and sometimes even different types of knowledge about the same phenomenon (Housinga Noroum et al. as cited in Emadi and Abbasi, 1999, p. 175). Therefore, to create databases, the ecological knowledge of both genders should be considered so as to help expand the domain of knowledge.

b). For the protection of natural resources and ecological balances, local ecological knowledge is to be used in line with sustainable development. This is because this type of knowledge as well as local skills has been acquired throughout centuries and contains considerable tested experiences.

c). Encouraging people and authorities to use a combination of indigenous and modern knowledge and technologies is necessary for effective and sustainable use of natural resources and safeguarding the planet for the present and future generations.

\section{Acknowledgements}

This research did not receive any specific grant from funding agencies in the public, commercial, or not-forprofit sectors.

\section{Conflict of Interest}

The authors declared no conflict of interests

\section{References}

Ahmadrash, R., \& Daneshmehr, H. (2015). The indigenous knowledge and development. Tehran, Iran: Sociologists Publications.

Amiri Ardakani, M. (2009). General ecology. Tehran, Iran: University of Tehran Press.

Amiri Ardakani, M. (2016). Indigenous knowledge in pedology. Tehran, Iran: The Center for Research and the Investigation of Rural Issues, Jihad Agricultural Research and Education Organization.

Appleton, H. (1993). Gender, technology and innovation. Appropriate Technology, 20(2), 6-8.

Azkia, M., \& Imani, A. (2008). Rural sustainable development. Tehran, Iran: Etelaat.
Bouzarjomehri, K. (2003). The position of indigenous knowledge in sustainable rural development. The Journal of Spatial Planning, 1(2), 5-20.

Bouzarjomehri, K., \& Javanshiri, M. (2015). Identify in indigenous knowledge and its application in rural crisis management by emphasizing drought, flood and earthquake (Case study: Zuzan in Khaf Province). Journal of Applied Environmental and Biological Science, 5(8S), 256-263.

Chang'a, L. B., Yanda, P. Z., \& Ngana, J. (2010). Indigenous knowledge in seasonal rainfall prediction in Tanzania: A case of the South-western Highland of Tanzania. Journal of Geography and Regional Planning, 3(4), 66-72.

DeAngelis, K. (2013). Building resilience to climate change through indigenous knowledge - the case of Bolivia. Retrieved from https://cdkn.org/resource/building-resilienceto-climate-change-through-indigenous-knowledge-the-caseof-bolivia/?loclang=en_gb:

Emadi, M. (1999). Indigenous knowledge is part of cultural wealth and is the heritage of our society thinking. The Special Issue of Traditional Sciences and Technologies (11-12), 122128.

Emadi, M. H., \& Abbasi, A. (2004). Integrating indigenous knowledge with conventional science: The necessity of achieving the rural agricultural development. Agricultural Economics and Development, 10(37), 11-36.

Feldstein, H. S., \& Poats, S. V. (Eds.). (1988). Working together: Gender analysis in agriculture. Hartford, CT: Kumarian.

Fernandez, M. E. (1994). Gender and indigenous knowledge. Indigenous Knowledge \& Development Monitor, 2, 6-7.

Golzari, A., \& Mirdamadi, S. (2010). Indigenous knowledge as an applied approach in sustainable development. Journal of Agriculture and Natural Resources Engineering Organization, 8(20), 28-32.

Gorjestani, N. (2000). Indigenous knowledge for development: Opportunities and challenges Retrieved from http://documents.worldbank.org/curated/en/574381468765625385/ pdf/multi0page.pdf

Grenier, L. (1998). Working with indigenous knowledge, a guide for researchers. Ottawa, Canada: The International Development research Centre.

Housinga Noroum, R., Yoder, R., \& Youlanda, M. (1999). The indigenous knowledge of women and agricultural development in the third world. The Role of Indigenous Knowledge in Sustainable Development, 33, 169-186.

Jomehpour, M. (2005). An introduction to rural planning. Tehran, Iran: SAMT.

Kalanda-Joshua, M., Ngongondo, C., Chipeta, L., \& Mpembeka, F. (2011). Integrating indigenous knowledge with conventional science: Enhancing localised climate and weather forecasts in Nessa, Mulanje, Malawi. Physics and Chemistry of the Earth, Parts A/B/C, 36(14), 996-1003.

McGregor, D. (2004). Coming full circle: Indigenous knowledge, environment, and our future. The American Indian Quarterly, 28(3-4), 385-410. 
McStay, J. R., \& Dunlap, R. E. (1983). Male-female differences in concern for environmental quality. International Journal of Women's Studies, 6(4), 291-301.

Nkomwa, E. C., Joshua, M. K., Ngongondo, C., Monjerezi, M., \& Chipungu, F. (2014). Assessing indigenous knowledge systems and climate change adaptation strategies in agriculture: A case study of Chagaka village, Chikhwawa, Southern Malawi. Physics and Chemistry of the Earth, Parts A/B/C, 67-69(Supplement C), 164-172.

Papzan, A., Hosseini, M., Azkia, M., \& Emadi, M. (2003). Predominant strategies for rural development: To make indigenous knowledge scientific and to make scientific knowledge indigenous. Paper presented at the Conference of Rural Development, Challenges and Perspective, Tehran, Iran.

Quiroz Consuelo(1994), "Local Knowledge systems contribute to sustainable development"IKMonitor.4(1)P:1-5.

Rattan, L. (1999). Permanent use of water and soil resources (M. A. Haj Abbasi, Trans.). Mashhad, Iran: Academic Center for Education, Culture and Research Press.

Tirivarombo, S., \& Hughes, D. A. (2011). Regional droughts and food security relationships in the Zambezi River Basin. Physics and Chemistry of the Earth, Parts A/B/C, 36(14), 977-983.

Vazin, N., \& Roknoldin Eftekhari, A. (2012). The role of indigenous knowledge in water and soil resources preservation from the perspective of the villagers: A case study of Khvoresh Rostam District, Khalkhal. Journal of Village and Development, 15(4), 91-114.

Warren, M., \& Cashman, K. (1988). Indigenous knowledge for sustainable agriculture and rural development. London, England: International Institute for Environment and Development.

Wishewa, R. (1993). Indigenous Knowledge, national IK resource centers and sustainable development Indigenous Knowledge and Development Monitor, 1(3), Online. 
